Journal of Engineering and Applied Sciences 14 (20): 7771-7777, 2019

ISSN: 1816-949X

(C) Medwell Journals, 2019

\title{
Influence of Si-69 Treated Hybrid Carbon Black/Precipitated Calcium Carbonate Filler on the Crosslink Density and Physico-Mechanical Properties of NR/SBR Blends
}

\author{
${ }^{1,2}$ Siti Nur Liyana Mamauod, ${ }^{2}$ Nor Atiqah Suhaimi, ${ }^{2}$ Rossuriati Dol Hamid, \\ ${ }^{2}$ Amirah Amalina Ahmad Tarmizi and ${ }^{3}$ Siti Salina Sarkawi \\ ${ }^{1}$ Centre of Polymer Composites Research and Technology (PoCResT), \\ Institute of Science, Universiti Teknologi MARA (UiTM), 40450 Shah Alam, Selangor, Malaysia \\ ${ }^{2}$ Faculty of Applied Sciences, Universiti Teknologi MARA (UiTM), \\ 40450 Shah Alam, Selangor, Malaysia \\ ${ }^{3}$ Technology and Engineering Division, Malaysian Rubber Board 47000, \\ Sg. Buloh, Selangor, Malaysia \\ nurliyana2219@salam.uitm.edu.my,+603-55435527
}

\begin{abstract}
Surface treament of Carbon Black (CB) and Precipitated Calcium Carbonate (PCC) was successfully prepared and used as a reinforcement in Natural Rubber and Styrene Butadiene Rubber (NR/SBR) blends. The effect of different concentration of tetra bis (3-(triethoxysilyl) propyl) tetrasulfide silane coupling agent (Si-69) ranging from 2-10 wt. \% on the $\mathrm{CB} / \mathrm{PCC}$ surface was studied by calculating the crosslink density formed between rubber and filler phases using Flory-Rehner equation. The data for Flory Rehner equation was obtained by swelling measurement. And also, the physical and mechanical of Si-69 treated CB/PCC reinforced NR/SBR blends was investigated. The amount of $\mathrm{CB}$ and $\mathrm{PCC}$ was set to be fixed. It was shown from the experimental results that $6 \%$ of Si-69 solution was the optimum concentration which exhibited the highest crosslink density developed between filler and rubber matrix phases as compared to the other treated and untreated samples. Up to $6 \%$ of Si-69 concentration gave the plasticizing effect on the filler surface resulting in reduction of physical and mechanical properties of NR/SBR blends. Apart from that the obtained results indicated that treated $\mathrm{CB} / \mathrm{PCC}$ filler at 6 wt.\% Si- 69 concentration exhibited better overall physical and mechanical properties due to good filler-rubbermatrix interfacial bonding.
\end{abstract}

Key words: Silane coupling agent, physical and mechanical properties, crosslink density, filler-rubbermatrix, natural rubber and styrene butadiene rubber, Carbon Black (CB)

\section{INTRODUCTION}

A successful method for preparing new polymeric materials having not only the main properties of the blends components but also new modification as well as new specific ones has been proved by blending of polymeric material. A polymer blend is a mixture of two or more polymers that have been blended together to create a new material with different physical and mechanical properties. Blending of two or more elastomers are employed in rubber products for a few of reasons which include improved physical and mechanical properties, easier processing and reduced product cost. Natural rubber and styrene butadiene rubber are conventional rubbers with wide use due to good abrasion resistance of
SBR and excellence stress strength of NR. However, there are deficiencies in some aspect limit the range of their applications (Ulfah et al., 2015). Many studies have proven that blending of NR and SBR was improved the balance properties like heat build-up, abrasion and aging resistance (Attharangsan et al., 2012; Romli and Mamauod, 2017; Tarantili, 2013; Sae-oui et al., 2016). The properties become more interesting with the incorporation of hybrid filler such as carbon black/silica (Ulfah et al., 2015), carbon black/rice husk (Attharangsan et al., 2012), nanoclay/nanosilica (Mamauod et al., 2017).

Fillers are incorporated into rubber matrix as a reinforcing material and to reduce the cost. Reinforcement is defined as enhancement of physical and mechanical properties such as tensile strength, abrasion resistance,

Corresponding Author: Siti Nur Liyana Mamauod, Centre of Polymer Composites Research and Technology (PoCResT), Institute of Science, Universiti Teknologi MARA (UiTM), 40450 Shah Alam, Selangor, Malaysia, nurliyana2219@salam.uitm.edu.my,+603-5543 5527 
hardness, rebound resilience and modulus. Degree of reinforcement determined the magnitude of adhesive bonding between filler and rubber matrix, the level of distribution of filler in rubber matrix and filler structure network. Those factors influenced the performance of reinforcing filler in enhancing the properties of polymer blends.

Carbon black is the most important reinforcing filler in rubber industries and it exhibits high tensile strength, abrasion resistance and modulus and tear strength (Attharangsan et al., 2012) while precipitated calcium carbonate is one of the most inexpensive and recyclable resources and it is widely used in polymer processing and acts as a filler (Tarantili, 2013). CB fillers are inorganic character poses a serious challenge in their effective use and so, it not well compatible with rubber matrix which is organic. Difference in characters had limits the dispersion of fillers in rubber matrix and causes an aggregation phenomenon between filler-filler particles. And if the filler-filler interactions are very strong. It would be difficult to interact with rubber interphase thus producing filler structure networks. Therefore, in order to get an appreciable influence on the dispersion and synergistic action of CB and PCC into NR/SBR matrix properties a significant modification is needed. The modification could be chemical or physical and this treatment produces and increases number of active sites on the surface of both $\mathrm{CB}$ and PCC fillers. The activation of both treated $\mathrm{CB} / \mathrm{PCC}$ surfaces increase higher surface reactivity contribute to the effective fibrematrix interaction. This leads an improvement of crosslink interaction between filler-rubber phases resulting in an increase in physical and mechanical properties. The purpose of this research work was to evaluate the effect of different concentration of Si-69 solutions on the behaviour of $\mathrm{CB} / \mathrm{PCC}$ as a reinforcing filler towards the crosslink density and physico-mechanical properties of NR/SBR blends.

\section{MATERIALS AND METHODS}

Natural rubber (SMR 10), Styrene Butadiene Rubber (SBR 1502) and Epoxidized Natural Rubber (ENR-compatibilizer) was purchased from Malaysian Rubber Board (MRB). Silane coupling agent type Si 69 (Bis (3-(triethoxysilyl) propyl) tetrasulfide) was supplied by Sigma Aldrich Sdn. Bhd. Other compounding ingredients used were of analytical grade.

Part A; Surface modification of CB/PCC by Si-69 solution: $\mathrm{Si}-69$ solutions were prepared at different $\mathrm{Si}-69$ content from $2-10 \%$ by weight (wt.\%) of the hybrid (a)

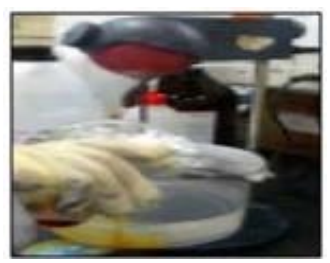

(c)

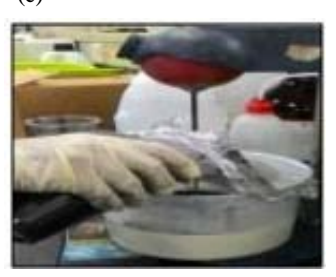

(b)

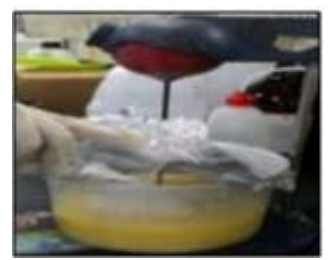

(d)

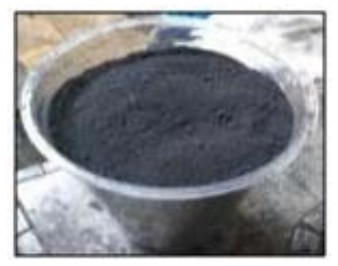

Fig. 1: Sequences for surface treatment of carbon black and precipitated calcium carbonate fillers: a) Addition of Si-69 into the ethanol; b) Addition of PCC into the solution of Si-69; c) Addition of CB into the mixture of Si-69 and PCC and d) Treated $\mathrm{CB} / \mathrm{PCC}$ hybrid filler

$\mathrm{CB} / \mathrm{PCC}$ filler. Si-69 solution was prepared by dissolving a specific amount of Si-69 content in ethanol. These Si-69 solutions were used to treat the surface of $\mathrm{CB}$ and PCC filler. For example, 2 wt.\%. of $\mathrm{Si}-69$ solution was prepared by mixing $1.8 \mathrm{~g}$ of the Si-69 and $100 \mathrm{~mL}$ of ethanol together and stirred for about $30 \mathrm{~min}$. The $90 \mathrm{~g}$ of $\mathrm{CB}$ and PCC filler was added into the Si-69 solution and again stirred for another $15 \mathrm{~min}$ to allow the products that produced from the hydroxylation process of silane to attack the $\mathrm{CB} / \mathrm{PCC}$ surface to form an Interpenetrating Polymer Networks (IPNs) with improved the interfacial interaction and adhesion between both $\mathrm{CB} / \mathrm{PCC}$ and NR/SBR phases. The treated hybrid filler will then dried at $100^{\circ} \mathrm{C}$ for $12 \mathrm{~h}$ in an oven until achieve a constant weight to allow complete evaporation of the ethanol. Similarly, 4 , 6,8 and 10 wt. $\%$ of Si-69 solutions were prepared by varying the initial $\mathrm{Si}-69$ contents for $90 \mathrm{~g} \mathrm{CB} / \mathrm{PCC}$ hybrid filler using the same procedure as mentioned above. Figure 1 shown the sequences of preparing the treated $\mathrm{CB} / \mathrm{PCC}$ filler.

Part B; Fabrication of Si-69 treated CB/PCC reinforced NR/SBR composites: It is compulsory to do mastication process first before proceeding to another process in order to achieve better dispersion of compounding ingredients into the rubber matrices. Mastication process must be done in order to breakdown and transform the high molecular weight, long and entangled polymer chains of NR/SBR to low viscosity for enhancing and facilitating 


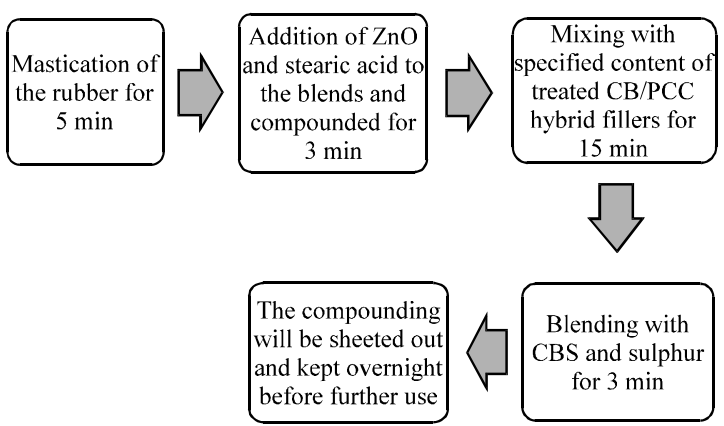

Fig. 2: Compounding process of the Si69 treated CB/PCC-NR/SBR composites

Table 1: Formulation of $\mathrm{Si}-69$ treated CB/PCC-NR/SBR composites

\begin{tabular}{lrrrrrr}
\hline Ingredient & F1 & F2 & F3 & F4 & F5 & F6 \\
\hline NR & 60 & 60 & 60 & 60 & 60 & 60 \\
SBR & 40 & 40 & 40 & 40 & 40 & 40 \\
Compatibilizer & 10 & 10 & 10 & 10 & 10 & 10 \\
PCC & 40 & 40 & 40 & 40 & 40 & 40 \\
CB & 50 & 50 & 50 & 50 & 50 & 50 \\
Si-69 & 0 & 2 & 4 & 6 & 8 & 10 \\
ZnO & 5 & 5 & 5 & 5 & 5 & 5 \\
HST & 2 & 2 & 2 & 2 & 2 & 2 \\
CBS & 1.2 & 1.2 & 1.2 & 1 & 1.2 & 1.2 \\
Sulfur & 1.8 & 1.8 & 1.8 & 2 & 1.8 & 1.8 \\
\hline
\end{tabular}

the compounding process and also improving the dispersion of other compounding ingredients. This process was done at room temperature by using a laboratory two-roll mill. The compounding process of the treated $\mathrm{CB} / \mathrm{PCC}$ reinforced NR/SBR blends is as shown in Fig. 2. The rubber was masticated for $5 \mathrm{~min}$ and the activator $(\mathrm{ZnO})$ and co-activator (stearic acid) will be added and compounded for $3 \mathrm{~min}$. Next, the blends was mixed with a specified content of treated $\mathrm{CB} / \mathrm{PCC}$ fillers for another $15 \mathrm{~min}$. After that, the accelerator (CBS) was added and lastly the curing agent (sulphur) was mixed and the unvulcanized was compounded for another $3 \mathrm{~min}$ and the compounds then was sheeted out and kept overnight before further use. The Si-69 treated CB/PCC-NR/SBR composites formulations were presented in Table 1.

\section{Characterization of Si-CB/PCC reinforced NR/SBR composites}

Determination of crosslink density by swelling: Swelling measurement was conducted based on the ASTM 471 . The compression moulded samples were cut with dimension $\left(2 \times 2 \times 2 \mathrm{~cm}^{3}\right)$ and weighed and immersed in toluene at room temperature for $24 \mathrm{~h}$ before the first reading was taken. The weight of sample was recorded until the reading reach an equilibrium state. The degree of crosslink density was calculated using Flory-Rehner equation as shown in Eq. 1:

$$
-\operatorname{In}\left(1-\mathrm{V}_{\mathrm{r}}\right)-\mathrm{V}_{\mathrm{r}}-\psi \mathrm{V}_{\mathrm{r}}^{2}=2 \rho \mathrm{V}_{0}[\mathrm{X}]_{\text {phy }} \mathrm{V}_{\mathrm{r}}^{1 / 3}
$$

Where:

$\mathrm{V}_{\mathrm{r}}=$ The Volume fraction of rubber

$\psi=$ The rubber-solvent interaction parameter

$\rho=$ The density of the polymer

$V_{0}=$ The molar Volume of the solvent

Physical and mechanical measurements: The tensile stress-strain properties of Si-69 treated CB/PCC-NR/SBR composites was carried out by using Instron 3366 tensile tester. The results of the tensile strength, elongation at break and modulus were determined, according to the standard ASTM D412. The dumbbell shaped samples were tested at crosshead speed of $500 \mathrm{~mm} / \mathrm{min}$ with using a $20-\mathrm{kN}$ load cell. The obtained results are reported as an average value calculated from five samples. The hardness was measured with the use of a Shore type a durometer and the circular shaped specimens with $6 \mathrm{~mm}$ thickness were prepared and tested. The rebound resilience test was carried out using a Schob machine. The circular shaped samples with $6 \mathrm{~mm}$ thickness were tested where the average was calculated based on the five samples for each formulation. The XRD patterns were recorded by a Philips diffractometer. Bragg's law is defined as $\lambda=2 \mathrm{~d} \sin \theta$ and it was used to compute the crystallographic spacing (d) for the unmodified and modified carbon black and precipitated calcium carbonate.

\section{RESULTS AND DISCUSSION}

Crosslink density: The development of 3D-networks between filler and rubber matrix surfaces is influenced by surface reactivity of filler. High surface reactivity of fillers enhancing the formation of strong filler-rubber matrix interphase interaction, thus, increasing the resistance to swell. High swelling resistance represents to high crosslink density. Figure 3 shows that the Si-69 surface treatment on $\mathrm{CB} / \mathrm{PCC}$ surface causing a reduction of crosslink density at 2 and 4 wt. $\%$ and it might be due to insufficient concentration of $\mathrm{Si}-69$ to attach to active sites of carboxylic (-COOH) and hydroxyl $(-\mathrm{OH})$ group of carbon black and hydroxyl (-OH) group of PCC that presented on the CB/PCC surface. So, less crosslink interaction between treated $\mathrm{CB} / \mathrm{PCC}$ and rubber matrix phases. However, excessive of Si-69 concentration for surface treatment of filler also, leading to a plasticizing effect and cause a reduction of crosslink density. It is clearly observed that the optimum Si-69 concentration achieved at $6 \mathrm{wt} . \%$ and it generates maximum active sites on the filler surface which form more compact crosslinking structures in Si-69 treated CB/PCC-NR/SBR blends than untreated and other treated blends. 


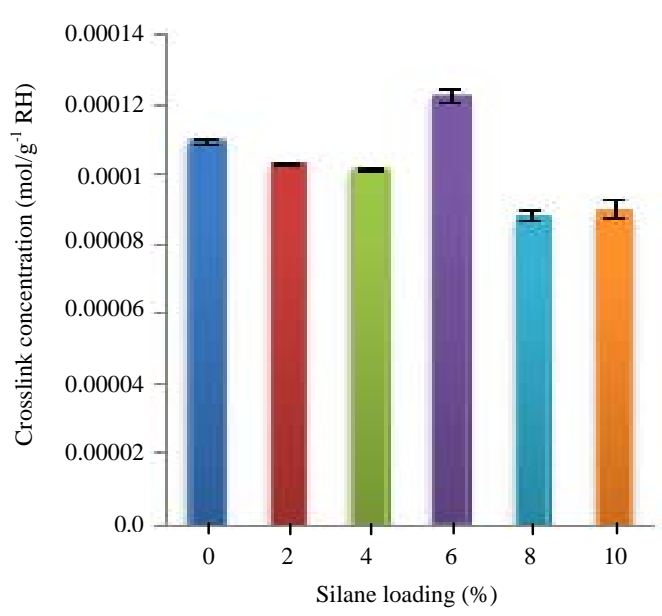

Fig. 3: Percentage of Si-69 concentrations treated $\mathrm{CB} / \mathrm{PCC}$ reinforced NR/SBR composites

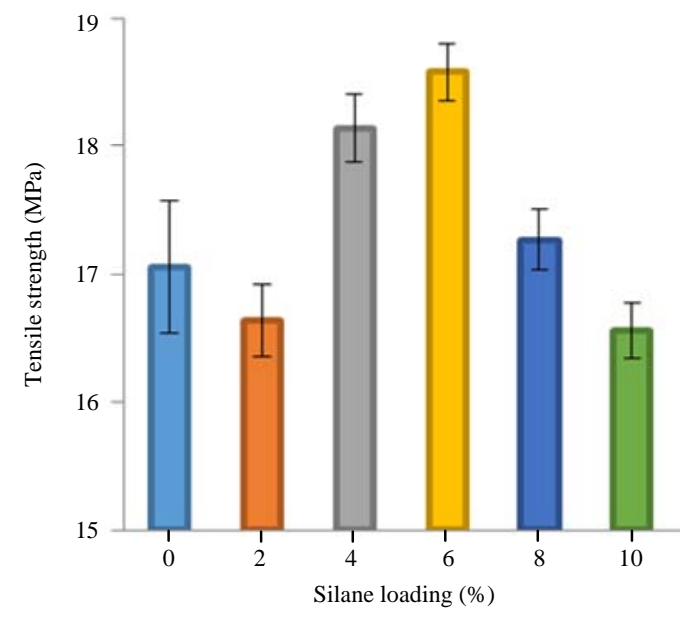

Fig. 4: Effect of Si-69 solution concentration on the performance of treated $\mathrm{CB} / \mathrm{PCC}$ reinforced $\mathrm{NR} / \mathrm{SBR}$ composites on tensile strength

Tensile strength: Figure 4 presents the tensile strength of Si-69 treated CB/PCC-NR/SBR composites with different percentage of Si-69 concentrations on the surface of $\mathrm{CB} / \mathrm{PCC}$ reinforced NR/SBR blends. In general, sufficient activation filler surface by Si-69 treatment would provide maximum interaction between filler and rubber phases. The degree of interaction can be assessed from the crosslink density behaviour and it directly influenced the tensile strength property. The result obtained shows an increase in strength of the sample up to $6 \mathrm{wt} \%$ of Si-69 loading and started to decrease as the percentage of Si-69 increase to 8 and 10 wt. \%. At 6 wt. \% of Si- 69 treated $\mathrm{CB} / \mathrm{PCC}-\mathrm{NR} / \mathrm{SBR}$ composites shows the maximum improvement due to effective degree of crosslinking, thus, producing a strong and effective formation interaction

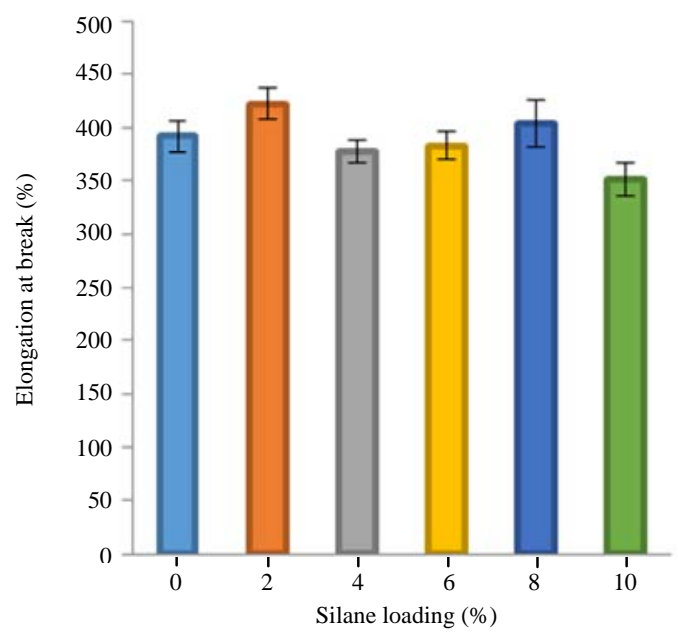

Fig. 5: Effect of Si-69 solution concentration on the performance of treated $\mathrm{CB} / \mathrm{PCC}$ reinforcedNR/SBR composites on elongation at break

with NR/SBR phases. It revealed that the higher tensile strength was achieved at optimum Si-69 concentration which give a good impact in term of stress transferring between rubber-filler interphase. As can be seen that the strength of the sample decrease about $2.25 \%$ from the sample with no Si-69 content as $2 \%$ of Si-69 is used to treat the surface of hybrid filler. The strength increases by about 8.29 and $10.66 \%$ from the rubber sample with $2 \%$ Si-69 when 4 and $6 \%$ of Si-69 is used to treat the fillers, respectively. After the optimum concentration ( -6 wt. \%) of Si-69 is achieved a gradual decrease of the tensile strength occurs and it is attributed due to the plasticizing effect of Si-69 structure and also, the function of Si-69 turns to plasticizer. In other words, it can be said that the higher loading of Si-69 concentration causing the Si-69 molecules to interact with primary and secondary hydroxyl of treated Si-69 and functional groups of filler surface leading to the plasticizing and flexiblizing phenomenon, thus, reducing the interfacial bond of filler and rubber matrix (Attharangsan et al., 2012). As the optimum Si-69 loading is used to treat the filler's surface the crosslink concentration also increases, thus, more chain segments are introduced which enable to support higher tensile force. Therefore, tensile strength increases progressively with increasing crosslink concentration (Ahmadi and Shojaei, 2013).

Elongation at break: Figure 5 indicates that the magnitudes of elongation at break are fluctuating as the amount of Si-69 increase. It can be concluded that the elongation at break of the rubber samples does not significantly affected by the different concentration of Si-69 used to treat the filler surface. 


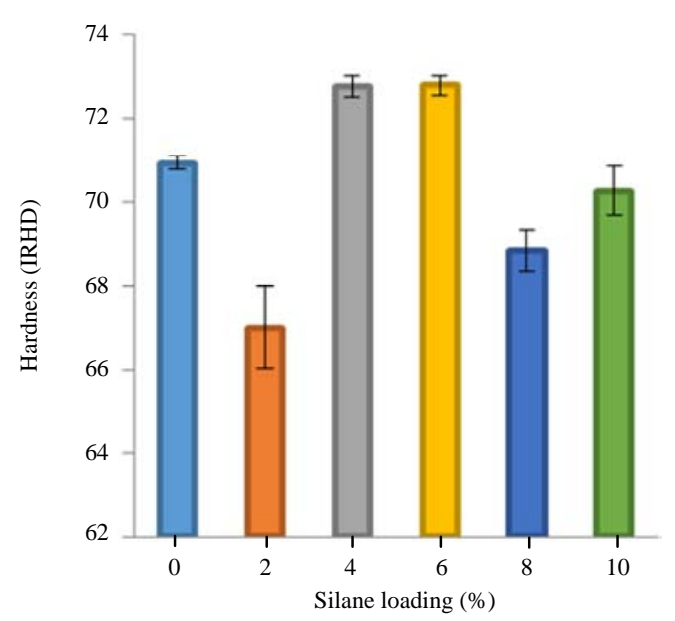

Fig. 6: Effect of Si-69 solution concentration on the performance of treated $\mathrm{CB} / \mathrm{PCC}$ reinforced NR/SBR

Hardnes: Figure 6 shows the hardness results of the treated $\mathrm{CB} / \mathrm{PCC}-\mathrm{NR} / \mathrm{SBR}$ blends at different Si-69 concentrations. The sample with $6 \%$ of silane loading shows the highest hardness reading with $72.775 \mathrm{IRHD}$ which indicates that this sample is the hardest compare with others. The optimum content of Si-69 could be 6\% if the result of crosslink concentration is taken into account, since, the crosslink concentration of the sample with $6 \% \mathrm{Si}-69$ gives the highest value which is $1.2024 \times 10^{-4} \mathrm{~mol} \mathrm{~g}^{-1} \mathrm{RH}$. The changes in hardness reading could be discussed in terms of the crosslink concentrations and the continuity of rubber phases by the presence of $\mathrm{Si}-69$. It can be expected that rubber blends with optimum silane (Si-69) concentration tend to produce higher crosslink concentrations and more continuous phases as a result of chemical bonding between the rubber and filler particles. Higher crosslink concentration may attribute to a more rigid rubber vulcanite, thus, increas ed the hardness of the rubber. However, above the optimum Si-69 contents the hardness worsened and this might due to the plasticization effect of the Si-69 (Attharangsan et al., 2012). Therefore, we could say that hardness of rubber compound is directly proportional to the crosslink concentration (Ahmadi and Shojaei, 2013).

Rebound resilience: Rebound Resilience (RR) is a very basic form of dynamic test in which the test piece is subjected to one half-cycle of deformation only. The strain is applied by impacting the test piece with an indentor which is free to rebound after the impact. Rebound resilience is described as the ratio of energy

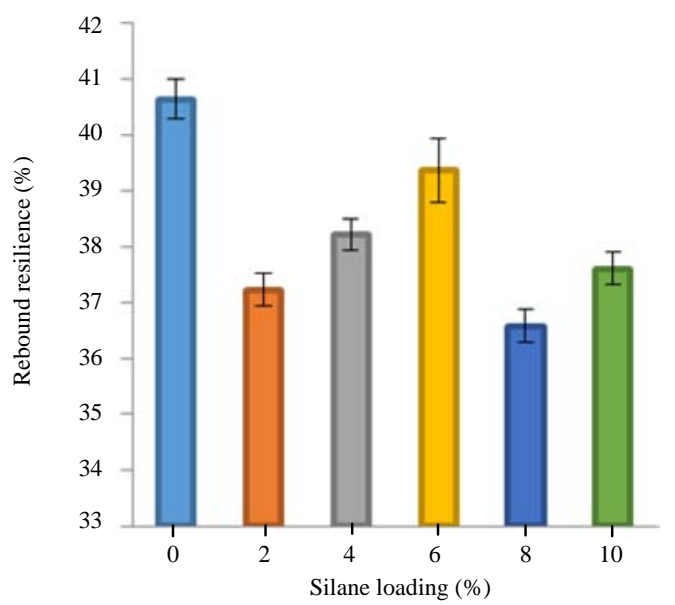

Fig. 7: Effect of Si-69 solution concentration on the performance of treated CB/PCC reinforcedNR/SBR composites on crosslink density

released by the recovery from deformation to that required to produce the deformation (Ahmadi and Shojaei, 2013). It is a measure of the ability of the rubber vulcanizates to return the energy used to deform it. Percentage of rebound resilience is commonly used in quality control testing of polymers and compounding chemicals. Figure 7 presents the almost same trend with other properties such as tensile strength and hardness. At 6 wt. $\%$ of Si- 69 treated CB/PCC-NR/SBR blend displayed the highest rebound resilience. It shows that the rubber sample had minimum ability to absorb the energy and high ability to return it as kinetic energy again. The $6 \mathrm{wt} . \%$ of Si-69 treated CB/PCC-NR/SBR sample also, shows high elasticity behaviour which is influenced by the high crosslink density. The uncontrolled crosslink distance (d) between crosslink points of Si-69 treated $\mathrm{CB} / \mathrm{PCC}$ and NR/SBR interphases led to the non-affine deformation which occur in the 3D network of non-homogeneous structure of sample Fig. 8. Apart from that, although, the crosslink density of sample is high but the probability of polymers to change from one configurational to another is also high upon to the applied energy. Whereas for untreated $\mathrm{CB} / \mathrm{PCCNR} / \mathrm{SBR}$ sample exhibited highest rebound resilience and it might be occur due to the flexibility in nature of both SBR and NR.

$\mathrm{X}$-Ray Diffraction (XRD) pattern: X-ray diffraction is used to determine the intercalated/exfoliated structure of $\mathrm{CB} / \mathrm{PCC}$ hybrid filler in the NR/SBR blends. From the XRD patterns in Fig. 9. The influence of Si-69 to the interlayer spaces between $\mathrm{CB} / \mathrm{PCC}$ filler and $\mathrm{NR} / \mathrm{SBR}$ are determined. The peak is shifted to a low degree of angle due to homogenize dispersion of treated hybrid filler in 


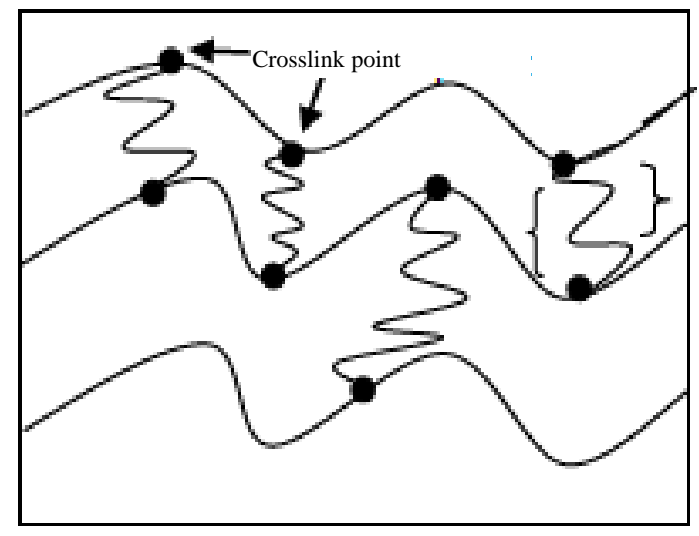

Fig. 8: Non homogeneous structure of $\mathrm{Si}-69$ treated $\mathrm{CB} / \mathrm{PCC}-\mathrm{NR} / \mathrm{SBR}$ composites

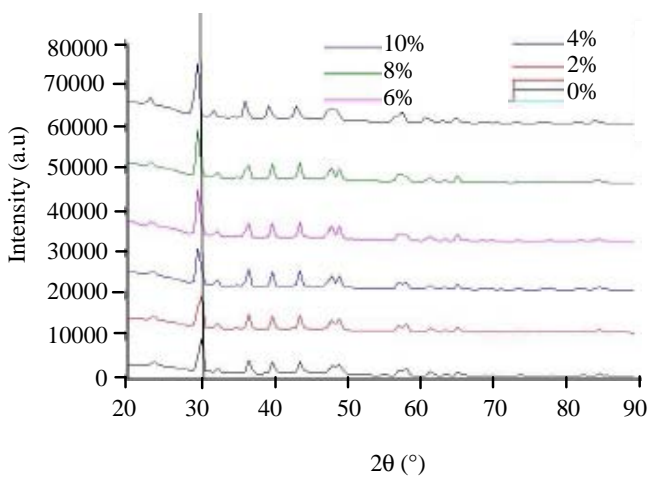

Fig. 9: Effect of Si-69 solution concentration on the performance of treated $\mathrm{CB} / \mathrm{PCC}$ reinforced NR/SBR composites on $\mathrm{XRD}$

the rubber matrix. This might be occurred due to present of Si-69 structure which had been introduced onto the filler phases, so that, both $\mathrm{CB} / \mathrm{PCC}$ layers were uniformly dispersed in the NR/SBR matrix which giving rise to an exfoliated structure. On the other hands, the polarity of Si-69 coupling agent and ENR would form a better interaction between nonpolar (NR/SBR) and polar (CB/PCC) phases. Increasing the Si-69 concentration led to lower tendency in filler agglomeration which resulted in good separation properties. The addition of untreated $\mathrm{CB} / \mathrm{PCC}$ in the rubber matrix has a tendency to form aggregates and intercalated filler structures. It is proven with the existence of peak at high value of angle. This peak is at $\mathrm{d}=3.03 \mathrm{~A}^{\circ}$. In this case, the presence of Si-69 and it structures are responsible in increasing the gap amongst the $\mathrm{CB} / \mathrm{PCC}$ primary particles.

\section{CONCLUSION}

Surface treatment of carbon black and precipitated calcium carbonate using Si-69 coupling agent had improved the surface reactivity of filler that would increase the crosslink density between filler and rubber matrix interphase interaction. The optimum Si- 69 solution concentration was achieved at $6 \mathrm{wt} \%$ based on the highest crosslink density formed between treated hybrid $\mathrm{CB} / \mathrm{PCC}$ and NR/SBR phases. At the optimum concentration of Si-69 it provides better physical and mechanical properties of Si-69 treated CB/PCC-NR/SBR composites as compared to others.

\section{ACKNOWLEDGEMENT}

This research work was sponsored by Institute of Research Management and Innovation, Universiti Teknologi MARA. The researchers are grateful to all staffs at Rubber Technology Laboratory for their kind help and support throughout this study.

\section{REFERENCES}

Ahmadi, M. and A. Shojaei, 2013. Cure kinetic and network structure of NR/SBR composites reinforced by multiwalled Carbon nanotube and carbon blacks. Thermochim. Acta, 566: 238-248.

Attharangsan, S., H. Ismail, M.A. Bakar and J. Ismail, 2012. Carbon Black (CB)/Rice Husk Powder (RHP) hybrid filler-filled natural rubber composites: Effect of $\mathrm{CB} / \mathrm{RHP}$ ratio on property of the composites. Polym. Plast. Technol. Eng., 51: 655-662.

Mamauod, S.N.L., A.Z. Romli and M.I.R. Rizuan, 2017. Synergistic effect of Nano Calcium Carbonate (NCC)/Carbon Black (CB) on the cure characteristics and physico-mechanical properties of NR/SBR blends. Proceedings of the 3rd International Conference on Electronic and Green Materials (EGM 2017) Vol. 1885, April 29-30, 2017, American Institute of Physics, College Park, Maryland, USA., ISBN:978-0-7354-1565-2, pp: 1-8.

Romli, A.Z. and S.N. Mamauod, 2017. Physical and mechanical properties of ENR compatibilizedNR/NBR blends reinforced nanoclay and nanosilica. Macromol. Symp., 371: 27-34.

Sae-oui, P., K. Suchiva, U. Thepsuwan, W. Intiya and P. Yodjun et al., 2016. Effects of blend ratio and SBR type on properties of silica-filled SBR/NR tire tread compounds. Rubber Chem. Technol., 89: 240-250. 
Tarantili, P.A., 2013. Reinforced Elastomers: Interphase Modification and Compatibilization in Rubber-Based Nanocomposites. In: Advances in Elastomers II, Visakh P., S. Thomas, A. Chandra and A. Mathew (Eds.). Springer, Berlin, Germany, ISBN:9783-642-20928-4, pp: 109-154.
Ulfah, I.M., R. Fidyaningsih, S. Rahayu, D.A. Fitriani and D.A. Saputra et al., 2015. Influence of Carbon black and silica filler on the rheological and mechanical properties of natural rubber compound. Procedia Chem., 16: 258-264. 